\title{
Relative survival following hemi-and total hip arthroplasty for hip fractures in Sweden

Szilard Nemes ${ }^{1,2 \dagger}$, Dennis Lind ${ }^{1,3^{*}}$ (D), Peter Cnudde ${ }^{1,2,4}$, Erik Bülow ${ }^{1,2}$, Ola Rolfson ${ }^{1,2}$ and Cecilia Rogmark ${ }^{1,3}$

\begin{abstract}
Background: Hip fractures are a common problem in the ageing population. Hip arthroplasty is the common treatment option for displaced intracapsular neck of femur fractures. Even though hip replacements are successful in restoring mobility, reducing pain and diminishing loss of health-related quality of life, the potential impact of a hip fracture on life expectancy as well as the postoperative mortality need consideration. The purpose of this study was to describe the mid-term relative survival rate for a cohort of Swedish patients whom underwent totalor hemiarthroplasty surgery following hip fracture. We also explored whether the survival rate is prosthesistype specific and influenced by comorbidities, sex, socioeconomic and surgical factors.

Methods: Using prospectively collected information of the Swedish Hip Arthroplasty Register-linked database we identified 43,891 patients operated between 2005 and 2012. Patient- and surgery-specific data in combination with socio-economic data were available for this analysis. We studied relative survival rate and used multivariable modelling with Cox Proportional Hazards Model in Transformed Time.

Results: Compared to the Swedish general population the baseline excess hazard was very high in the first half year after the operation, thereafter the excess hazard decreased but remained non-negligible through the 8 years' followup period. The mortality rate of males was higher compared to women. Higher Elixhauser comorbidity index (ECI) was associated with worsening survival. However, patients who had $\mathrm{ECl}=0$ had higher mortality than patients with $\mathrm{ECl}=1$ the first 420 days post fracture. Patients with a hemiarthroplasty had a worse survival than patients with a total hip arthroplasty. Of the hospital types considered university hospitals had lower survival rate. Younger patients had a greater loss of expected life span than patients who suffer hip fracture in their more advanced ages.
\end{abstract}

Conclusions: Swedish hip fracture patients who undergo arthroplasty surgery had a high excess hazard of dying in the first half year following surgery, and this excess hazard never subsided to negligible levels at least up to 8 years after surgery. Interestingly having no prior record of illnesses worsened the initial mortality. Men living alone had the highest long-term excess mortality.

Keywords: Hip fracture, Excess mortality, Relative survival, Hip arthroplasty

\section{Background}

From the onset of age 60 the residual life time risk for hip fracture for men and women is estimated to be around 5 and $10 \%$, respectively [1]. The number of hip fractures are bound to increase as the population becomes older [2]. It is well-known that hip fracture

\footnotetext{
* Correspondence: dennis.lind@med.lu.se

† Szilard Nemes and Dennis Lind contributed equally to this work.

'Swedish Hip Arthroplasty Register, Centre of Registers Västra Götaland, Gothenburg, Sweden

${ }^{3}$ Department of Orthopedics, Lund University, Skane University Hospital, Malmö, Sweden

Full list of author information is available at the end of the article
}

patients have a high risk of dying, but the literature is not concordant on how large the excess mortality is, compared to the general population of the same age, on how long time the excess risk prevails or if there are differences between the sexes $[3,4]$. In recent years, there has been an improvement in the immediate care of the hip fracture patient, with shorter time to surgery and mobilisation within the first postoperative day. There is however conflicting evidence as to whether this actually has led to reduced mortality. Pedersen et al. [5] found a significant decrease in 1-year mortality the last 35 years, whereas other studies on temporal trends did not $[6,7]$.

(c) The Author(s). 2018 Open Access This article is distributed under the terms of the Creative Commons Attribution 4.0 International License (http://creativecommons.org/licenses/by/4.0/), which permits unrestricted use, distribution, and reproduction in any medium, provided you give appropriate credit to the original author(s) and the source, provide a link to the Creative Commons license, and indicate if changes were made. The Creative Commons Public Domain Dedication waiver (http://creativecommons.org/publicdomain/zero/1.0/) applies to the data made available in this article, unless otherwise stated. 
The Swedish Hip Arthroplasty Registry (SHAR) provides a unique opportunity to study mortality on a large group of patients. Hip arthroplasty is considered the main treatment option for displaced femoral neck fractures for patients aged over 60 [8].

In this study, we aimed to identify the patients with the highest risk of dying after their fracture-related arthroplasty and to study the mortality, stratified by different patient, hospital and socioeconomic factors. Whilst previous studies have used the term absolute survival to study the increased risk, we intended to use techniques of relative survival analysis in an attempt to estimate and quantify the excess hazard introduced to our patients compared to the general population. We also studied if this excess hazard would either disappear in time, remain or continue to put the patient at higher risk of dying for several years after surgery.

\section{Methods}

\section{Patients and methods}

Since 2005 the SHAR registers hip fracture patients whom undergo both total and (or) hemiarthroplasty. We identified all patients operated between 2005 and 2012, and this patient group served as our study group. If a patient had sustained bilateral hip operations due to fractures, we only considered the first operation (Fig. 1). To adjust for confounding, accessible and relevant variables were collected from three registers. SHAR provided data about the patients' age at operation, sex, prosthesis type (hemiarthroplasty or total hip arthroplasty), and hospital type (rural, county, university or private). The SHAR is a Swedish quality register and has a high completeness (98\%) and full coverage (100\%) [8]. Date of death is continuously updated in SHAR. The risk of leakage out of the register was considered, however only a handful of patients are known to have asked for their data to be removed [9]. Emigration rate in this group of frail elderly Swedes can be considered very low, and similar to the general population of the same age. Those few patients who emigrated were censored as they were dead [9]. Using the Swedish unique 10 digit personal identity number we linked the data from SHAR to Statistics Sweden and the National Patient Register (NPR) (National Board of Health and Welfare) [10]. Statistics Sweden provided data about the patients' education and civil status, while the NPR delivered data about the patients' health status encoded as ICD-10 codes. Swedish hospitals are obliged by law to report all primary and secondary ICD-10-codes to the NPR for every contact with the hospital. Only individual with entries in all three registers were included. Individual ICD-10-codes were combined into Elixhauser comorbidity indices (ECI) for each patient $[11,12]$. The ECI is an unweighted comorbidity index representing the number of present comorbidities out of 31 possible. The ICD-10-codes were identified from hospital based healthcare in the year before the index hospital admission. Patents without recorded visits were classified as patients without known comorbidity (i.e. Elixhauser $=0$ ).

\section{Statistical methods}

We summarized continuous variables as means and standard deviations, categorical variables as counts and percentages. We used Student's t-test and $\mathrm{X}^{2}$-test for group comparisons. In this paper we used relative survival analysis $[13,14]$ The measure of interest was cumulative relative survival function $r(t)$. We estimated the cumulative relative survival function as $r(t)=\frac{S_{\mathrm{O}}(t)}{S_{\mathrm{p}}(t)}$.

Where $\mathrm{S}_{\mathrm{O}}(\mathrm{t})$ denotes the observed survival and $\mathrm{S}_{\mathrm{P}}(\mathrm{t})$ the population or expected survival at time $t$. We extracted the Swedish population or expected survival $\mathrm{S}_{\mathrm{P}}(\mathrm{t})$ from publicly available mortality tables tabulated for sex and age maintained by the Human Life-Table Database [15] and Human Mortality Data Base [16].

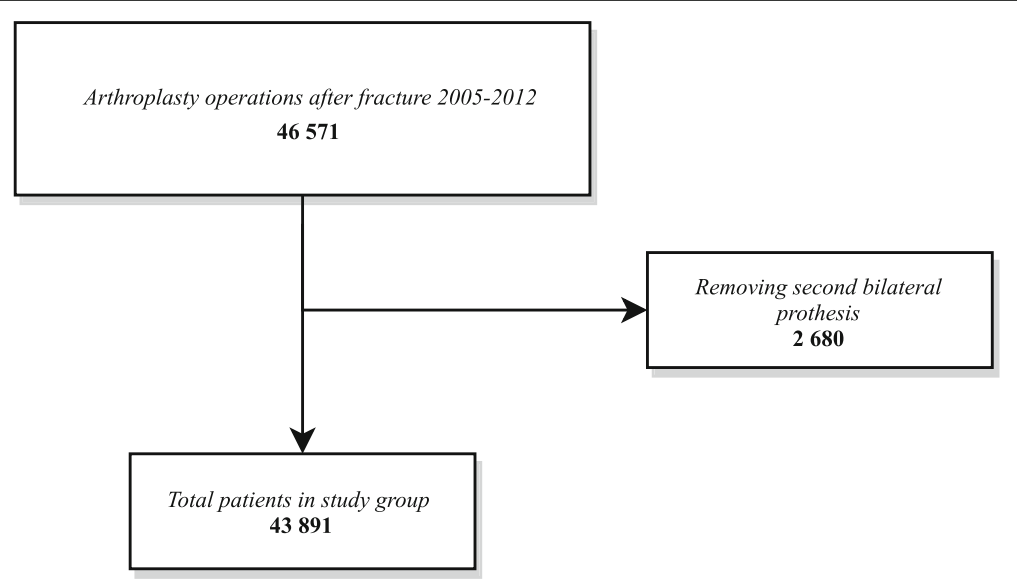

Fig. 1 Patient flowchart 
The cumulative relative survival function $r(t)$ can be any non-negative number. If $r(t)=1$, then the observed survival of the studied group coincides with the expected or population survival. If $\mathrm{r}(\mathrm{t})>1$ then the observed survival of the studied group exceed the expected or population survival. If $\mathrm{r}(\mathrm{t})<1$ then the studied group experiences an excess mortality. We can partition the observed hazard for each individual $\lambda_{\mathrm{O}}(\mathrm{t})$ into two additive components: $\lambda_{\mathrm{O}}(\mathrm{t})=\lambda_{\mathrm{P}}(\mathrm{t})+\lambda_{\mathrm{E}}(\mathrm{t})$.

The age- and sex-specific baseline hazard is denoted by $\lambda_{P}(t)$. The difference between the baseline hazard and observed hazard, $\lambda_{E}(t)$ denotes the excess hazard of the study group.

Alongside with the cumulative relative survival, the excess hazard and the cumulative incidence curve served as the main methods of analysis. Additionally, we attempted to model the effect of clinical and patient related covariates with the help of multivariable Cox Proportional Hazards Model in Transformed Time [17]. We tested the assumption of proportionality with graphical examination and Brownian bridges [18]. We observed violation of the proportionality assumption for prosthesis type, age and ECI. We modelled these variables by the introduction of a step function that split the data in two epochs up to 14 months (420 days) and the subsequent period until end of study period. The multivariable regression analysis included interaction term between the aforementioned variables and the step function for time.

\section{Results}

In the SHAR a total of 43,891 patients with hip arthroplasty surgery due to hip fracture were identified between 2005 and 2012(Fig. 1.) There was a female predominance $(70 \%)$ and the average age was 79 years for the survival group and 84 for the deceased group (Table 1).

As illustrated in Fig. 2 the baseline excess hazard of dying was elevated the first half year after the operation, thereafter the excess hazard decreased. However, it remained non-negligible trough the 8 years follow up period.

Table 1 Baseline demographic information for the study population stratified for survival status

\begin{tabular}{|c|c|c|c|c|}
\hline & Alive & Dead & Total & $P$-value \\
\hline Sample Size & 22,575 & 21,316 & 43,891 & \\
\hline Sex: Female (\%) & $16,857(74.7)$ & $13,988(65.6)$ & 30,845 & $<0.001$ \\
\hline Age (mean \& sd) & $79.33(9.17)$ & $83.85(7.77)$ & & $<0.001$ \\
\hline Hospital type (\%) & & & & $<0.001$ \\
\hline University & $5677(25.1)$ & $5916(27.8)$ & 11,593 & \\
\hline County & $12,089(53.6)$ & $11,299(53.0)$ & 23,388 & \\
\hline Rural & $3905(17.3)$ & $3351(15.7)$ & 7256 & \\
\hline Private & $904(4.0)$ & $750(3.5)$ & 1654 & \\
\hline Prosthesis: Total hip arthoplasty (\%) & $7887(34.9)$ & $2690(12.6)$ & 10,577 & $<0.001$ \\
\hline Education (\%) & & & & $<0.001$ \\
\hline Low & $12,309(54.5)$ & $12,695(59.6)$ & 25,004 & \\
\hline Middle & $6968(30.9)$ & $5740(26.9)$ & 12,708 & \\
\hline High & $2793(12.4)$ & $1914(9.0)$ & 4707 & \\
\hline Missing & $505(2.2)$ & $967(4.5)$ & 1472 & \\
\hline Civil status (\%) & & & & $<0.001$ \\
\hline Couple & $7971(35.3)$ & $6269(29.4)$ & 14,240 & \\
\hline Single & $5489(24.3)$ & $4417(20.7)$ & 9906 & \\
\hline Widow & $9071(40.2)$ & $10,620(49.8)$ & 19,691 & \\
\hline Missing & $44(0.2)$ & $10(0.0)$ & 54 & \\
\hline Elixhauser index (mean \& sd) & $1.13(1.35)$ & $1.27(1.53)$ & & $<0.001$ \\
\hline Elixhauser stratified (\%) & & & & $<0.001$ \\
\hline 0 & $9930(44.0)$ & $9534(44.7)$ & 19,464 & \\
\hline 1 & $5448(24.1)$ & $4087(19.2)$ & 9535 & \\
\hline 2 & $3754(16.6)$ & $3467(16.3)$ & 7221 & \\
\hline $3+$ & $3443(15.3)$ & 4228 (19.8) & 7671 & \\
\hline
\end{tabular}



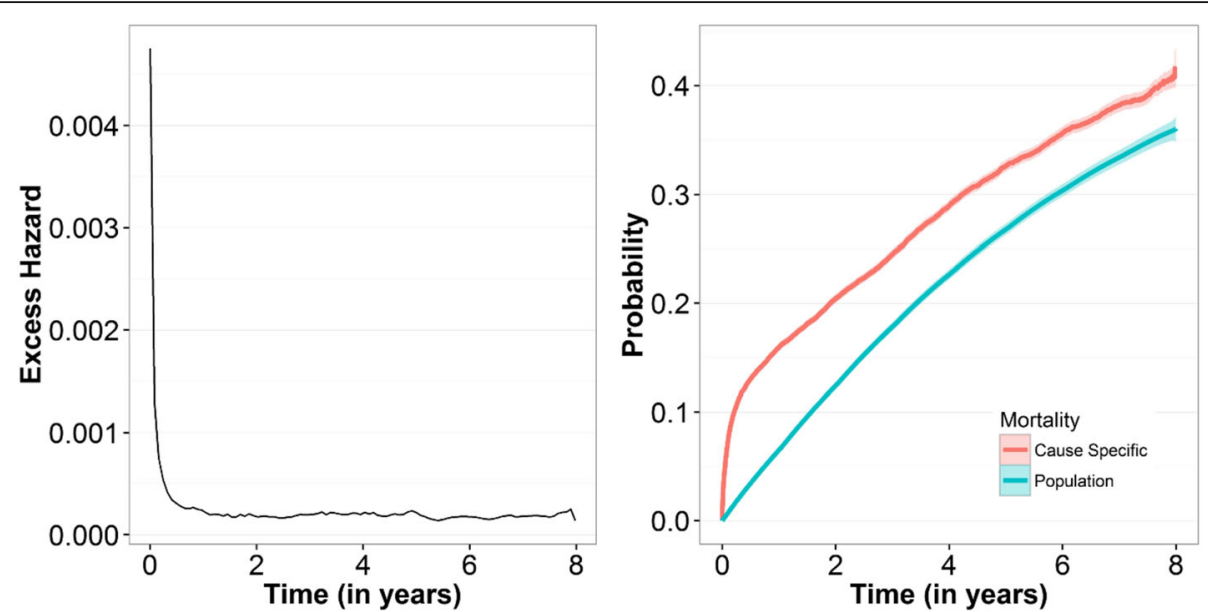

Fig. 2 Excess hazard and crude mortality curves for 43,891 Swedish hip fracture patients compared with the mortality rates of the Swedish general population

\section{Age and sex}

The mortality rate of males was higher, and both sexes had survival rates inferior than their peers from the general population (Fig. 3). Younger age, analysed as a continuous variable, led to an increased relative risk of dying, being more pronounced in the later period.

\section{Elixhauser comorbidity index}

In general, the higher the ECI the lower the survival was. But the group with a ECI of 1 had better survival during the first 420 days, compared with those with ECI of 0 (Fig. 3). Over time the negative effect of the increasing ECI on survival became more obvious.

\section{Implant and hospital type}

Patients with total hip arthroplasty had a better survival than patients with hemi-arthroplasty. Of the hospital types considered university hospitals had lower survival rate during the first 6 years, whilst patients operated at private, rural and county hospitals had similar survival rates. Over time, the impact of implant-type decreased (Fig. 3).

\section{Socioeconomics}

The separation of the survival rates for the different socioeconomic status was significant for education. Patients who completed higher levels of education had better survival that patients with low or middle education levels. (See Fig. 4) The later two categories had similar survival rates during the whole follow up period. Being married compared to being single and having higher achieved levels of education lowered the risk of death, however being a widow did not (Table 2). Multivariable relative survival regression corroborated most of the results of the univariate analysis.

\section{Discussion}

Main findings

Swedish hip fracture patients whom undergo hip arthroplasty had a high excess hazard of dying, up to 100 days after the operation compared with individuals in the general population of the same age and sex. This excess hazard diminished with time but never subsided to negligible levels. The mortality rate of hip fracture patients remained higher than the mortality rate of the general population during the whole 8 years' follow-up period.

Earlier papers have related the long-term mortality among hip fracture patients to the mortality rates in the general population $[3,4,6,19]$. These studies highlighted an increased mortality among hip fracture patients compared with the general population using age and sex standardization. We used relative survival rate and multivariable modelling and could therefore relate every patient to the survival rate of members of the general population of the same age and sex.

The excess early mortality can possibly be explained by the comorbidities and frailty of hip fracture patients, aggravated by the injury and the surgery. The relationship between fracture and increased risk of death up to 8 years post-surgery, is more difficult to disentangle. Apart from the chronic disease status in this patient population, previous research has suggested that pain and fear of falling [20] is contributing to a decrease in activity and exercise and a decrease in walking distance [21], which in turn potentially contributes to a loss of independence and depression [22]. In order to improve outcomes following hip fracture surgery, it is imperative to identify modifiable factors that could possibly aid survival and function [23]. There have been promising results where an improved and close cooperation between orthopaedic surgeons and geriatricians have led to a reduction in mortality [24] aided by systematic and sustained quality improvement efforts $[25,26]$. 

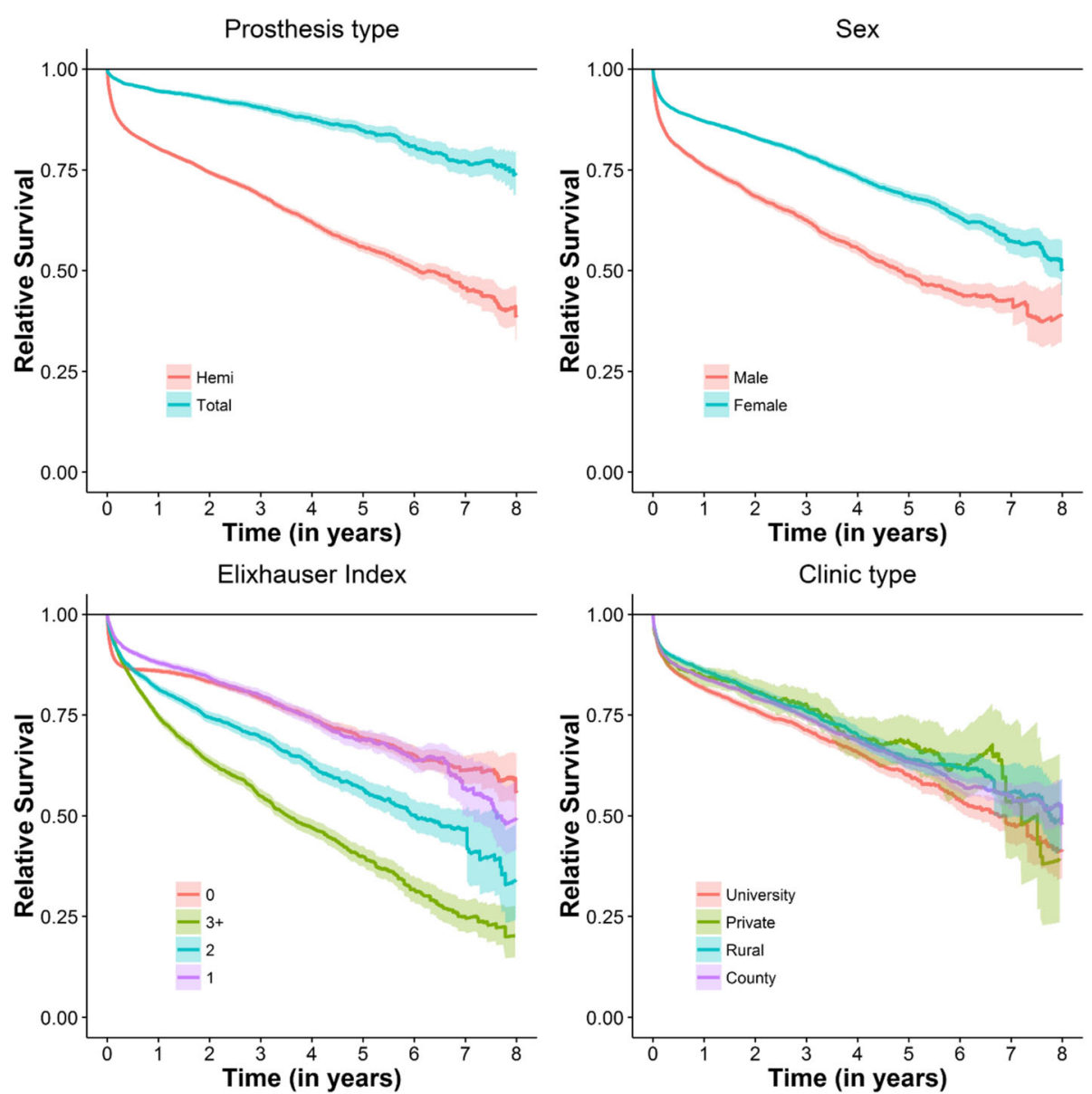

Fig. 3 Relative survival curves of 43,891 Swedish hip fracture patients stratified in patient and hospital related factors. If the survival curves deviates the horizontal reference line then the survival of the studied stratum differs significantly from the general population
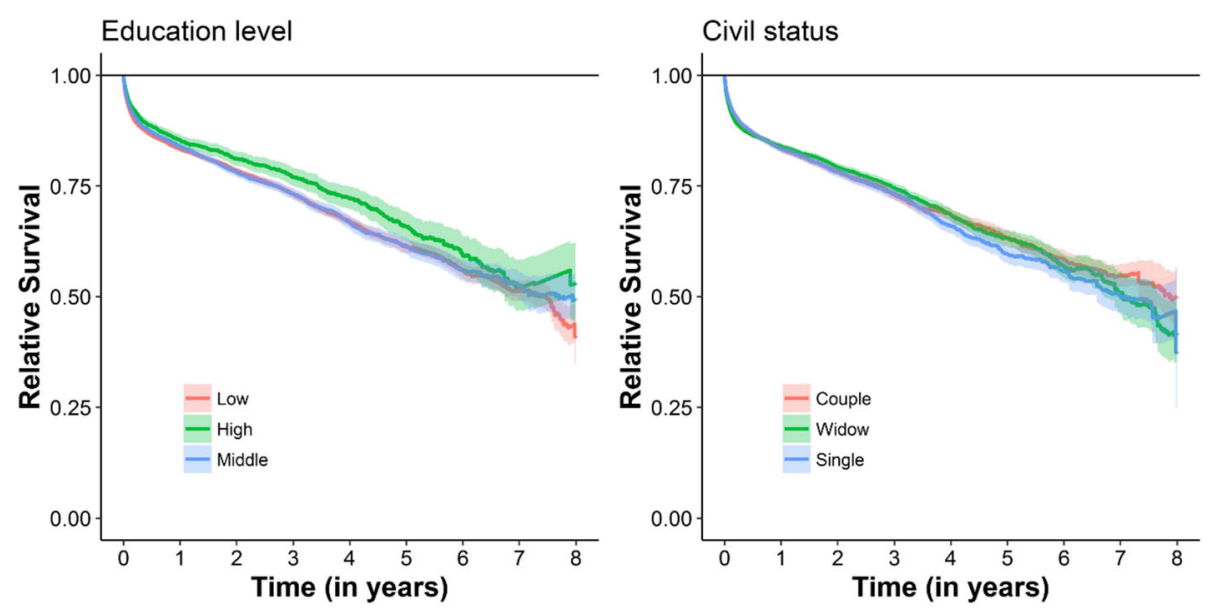

Fig. 4 Relative survival curves of 43,891 Swedish hip fracture patients stratified in Education level and Civil status. If the survival curves deviates the horizontal reference line then the survival of the studied stratum differs significantly form from the general population 
Table 2 Multivariable relative survival regression analysis of survival of Swedish hip fracture patients

\begin{tabular}{|c|c|c|}
\hline & $\mathrm{HR}$ & $95 \% \mathrm{Cl}$ \\
\hline \multicolumn{3}{|l|}{ Sex } \\
\hline Female & Ref & \\
\hline Male $0-420$ days & 2.48 & $2.37 ; 2.59$ \\
\hline Male $>420$ days & 2.32 & $2.11 ; 2.55$ \\
\hline \multicolumn{3}{|l|}{ Age } \\
\hline $0-420$ days & 0.94 & $0.94 ; 0.94$ \\
\hline$>420$ days & 0.91 & $0.90 ; 0.92$ \\
\hline \multicolumn{3}{|c|}{ Elixhauser $0-420$ days } \\
\hline 0 & Ref & \\
\hline 1 & 0.92 & $0.86 ; 0.97$ \\
\hline 2 & 1.23 & $1.16 ; 1.30$ \\
\hline+3 & 1.47 & $1.39 ; 1.55$ \\
\hline \multicolumn{3}{|l|}{ Elixhauser $>420$ days } \\
\hline 0 & Ref & \\
\hline 1 & 1.09 & $0.96 ; 1.24$ \\
\hline 2 & 1.30 & $1.15 ; 1.49$ \\
\hline+3 & 1.75 & $1.55 ; 1.97$ \\
\hline \multicolumn{3}{|l|}{ Year of operation } \\
\hline $0-420$ days & 1.00 & $0.99 ; 1.01$ \\
\hline$>420$ days & 0.99 & $0.99 ; 1.01$ \\
\hline \multicolumn{3}{|l|}{ Prosthesis } \\
\hline Hemi & Ref & \\
\hline Total 0-420 days & 0.38 & $0.35 ; 0.41$ \\
\hline Total $>420$ days & 0.54 & $0.46 ; 0.64$ \\
\hline \multicolumn{3}{|l|}{ Hospital } \\
\hline University & Ref & \\
\hline County & 0.95 & $0.92 ; 0.98$ \\
\hline Rural & 0.93 & $0.89 ; 0.97$ \\
\hline Private & 0.89 & $0.82 ; 0.95$ \\
\hline \multicolumn{3}{|l|}{ Education } \\
\hline Low & Ref & \\
\hline Middle & 0.99 & $0.96 ; 1.02$ \\
\hline High & 0.91 & $0.87 ; 0.95$ \\
\hline \multicolumn{3}{|l|}{ Civil status } \\
\hline Couple & Ref & \\
\hline Single & 1.08 & $1.03 ; 1.12$ \\
\hline Widow & 1.03 & $0.99 ; 1.06$ \\
\hline
\end{tabular}

\section{Age}

Advanced age is associated with an increase in mortality after hip fracture however, this may be due to the higher general mortality rates that comes with aging [27, 28], as we by relative survival analysis observed that age was positively associated with the relative survival. Patients who suffer a hip fracture in their younger years lost more of their expected life span than patients who had their fracture in more advanced age. This effect increased with the follow-up time. This finding suggests that especially in the younger hip fracture population, there could be a greater benefit of an improved collaboration between healthcare professionals within the hospital setting, general practitioners and the municipal social care.

\section{Sex}

The excess mortality of males was higher than for females. This was more evident in the beginning of the study period. Subsequently the excess sex-related differences in survival following hip fracture surgery follow a similar trends of the sex-related difference in survival of the general population. That men have a higher risk of dying after hip fracture is well known from the literature, and was shown also in an recent study [19]. It can be debated if this is induced by sex as an isolated variable, or if being male is a surrogate variable for comorbidity, unhealthy lifestyle or other confounders adding to their risk of both hip fracture and death.

\section{Elixhauser comorbidity index}

Generally patient comorbidity had a significant adverse effect on survival [28], even though moderate comorbidity may not be associated with an excess one-year-mortality [27-31]. The hazard rates increased with increased score of comorbidity, as measured by the ECI [32]. This effect became stronger with time. Interestingly, in the early period patients with $\mathrm{ECI}=1$ have higher survival rate than patients with $\mathrm{ECI}=0$, while after 420 days no such difference was seen. An attempted explanation could be that patients with known comorbidities are receiving increased medical attention prior to the surgery, improving their health status. The group of patients with an ECI $=0$ may consist of two types of patients; really healthy individuals and those who are not, but never sought medical attention and as such have undiagnosed and/or untreated comorbidity. Assumingly, in the hip fracture population there are a number of patients neglecting their health. These patients may present with an unstable medical condition at the time of their hip fracture, and subsequently have a higher risk of dying. We believe our results could question the validity of comorbidity indices based on administrative patient registers. Besides sick individuals not being known to the healthcare, there is a possibility of misdiagnosis bias due to incorrect coding [33].

\section{Hospital type}

We found lower relative survival of patients treated at university hospitals. Similar results has been described in a Danish study [34], whilst a Canadian study found an 
improved survival in teaching hospitals compared to community hospitals [35]. Finally, a study from the USA concluded that hospital volume did not predict mortality, even though hospitals with high caseload had fewer complications [36]. Swedish university hospitals typically serve an urban population, so when comparing different hospitals, we also compare different populations. Based on the available evidence one could conclude that both hospital level and volume are blunt variables confounded by case-mix, level of competence of the staff and an unclear definition of what high volume is, making comparisons between different healthcare systems difficult.

\section{Year of surgery}

The year of surgery was not associated with any excess risk of mortality, indicating that during our study period the rate between hip fracture patients survival and the survival of the general population did not change. This finding is in agreement with the findings of Klop et al. [37]. In a systematic review on randomized clinical trials, Mundi et al. found similar mortality in hip fracture patients over time [6].

\section{Implant type}

Patients operated with total hip arthroplasty had lower mortality than those with hemi-arthroplasty. This is most probably a reflection of selection bias as choice of implant is based on patient frailty, age and activity level.

\section{Socioeconomics}

Solitary life style [38] and social deprivation [39] have been previously associated with increased mortality after hip fracture. In our study we found similar results, where being non-married brought on a slight increase in mortality. However, in our study being widowed had no adverse effect on mortality.

\section{Strengths and limitations of the study}

Other factors may influence mortality. Solbakken and collaborators [40] concluded that self-perceived health, smoking, and BMI predict mortality of hip fracture patients. Vosoughi and collaborators [41] reached similar conclusions regarding smoking and BMI and noted improved nutrition as modifiable factors. Hence, as our register data is limited in terms of such variables, our results could not be adjusted for those and might have to be interpreted with caution due to varying degree of validity [42].

The SHAR has an excellent completeness of over $98 \%$ [8], in combination with the large patient cohort are the main strengths of the present study. The additional access to socioeconomic and comorbidity data from governmental administrative registers further add to the strength [10]. Additionally, the use of relative survival analysis has an overarching advantage that, through a single measure, it indicates the degree to which a study sample corresponds to the general population with respect to health status and survival [43].

\section{Perspective}

Orthopaedic healthcare of today focuses on a timely and effective treatment of hip fracture patients. Post-operative care can also be of a fast-track nature, both reflecting new scientific knowledge and health economic challenges. Concerns have been raised whether a shorter length-ofstay is associated with an increase in mortality [44]. Our findings may assist the clinician to identify patients at risk of excess mortality. The patient without prior medical records or diagnoses can actually be more challenging than expected. A younger patient will suffer a risk of a greater expected life span loss than the more elderly patient and this should not be neglected. The same goes for singles and/or males. The hip fracture patient in general carries a highly increased risk of dying during several months after fracture, compared to the general population, and further closer follow-up care have to be provided after discharge from the hospital.

\section{Conclusions}

Hip fracture patients, in particular males, have a considerable excess hazard of dying compared with the general population. Younger patients have a greater loss of expected life span than patients who suffer hip fracture in their more advanced ages. Existing comorbidities, lower education and solitary life style all have an adverse effect on survival. The survival rates of hip fracture patients did not improve during a study period of 7 years.

\section{Abbreviations}

ECl: Elixhauser comorbidity index; SHAR: The Swedish Hip Arthroplasty Registry

\section{Acknowledgements}

The authors thank the coordinators in Gothenburg for their tireless efforts in the Swedish Hip Arthroplasty Register. We are also grateful to all the reporting clinics in Sweden.

\section{Funding}

The study has not received any specific funding.

\section{Availability of data and materials}

The data that support the findings of this study are available from The Swedish Hip Arthroplasty Registry but restrictions apply to the availability of the data, used under license for the current study, and as such are not publicly available. Data are however available from the authors upon reasonable request and with permission of The Swedish Hip Arthroplasty Registry, and our ethical review boards approval.

\section{Authors' contributions}

Conceptual design: SN, DL, CR. Acquisition of data: SN, EB. Analysis of data: $\mathrm{SN}, \mathrm{EB}, \mathrm{DL}$. Interpretation of data: $\mathrm{DL}, \mathrm{CR}, \mathrm{PC}, \mathrm{OR}, \mathrm{SN}, \mathrm{EB}$. Drafting of manuscript: DL, SN, CR, PC, EB, OR. Revising of manuscript: $D L, C R, P C, E B, O R$, $\mathrm{SN}$. All authors read and approved the final manuscript. 


\section{Ethics approval and consent to participate}

Ethical review approval was obtained from the Central Ethical Review Board in Gothenburg, Sweden (decision 271-14). De-identified data was used in this study.

\section{Consent for publication}

Not applicable

\section{Competing interests}

The authors declare that they have no competing interests.

\section{Publisher's Note}

Springer Nature remains neutral with regard to jurisdictional claims in published maps and institutional affiliations.

\section{Author details}

${ }^{1}$ Swedish Hip Arthroplasty Register, Centre of Registers Västra Götaland, Gothenburg, Sweden. ${ }^{2}$ Department of Orthopedics, Institute of Clinical Sciences, Sahlgrenska Academy, University of Gothenburg, Gothenburg, Sweden. ${ }^{3}$ Department of Orthopedics, Lund University, Skane University Hospital, Malmö, Sweden. ${ }^{4}$ Department of Orthopedics, Hywel Dda University Healthboard, Prince Philip Hospital, Bryngwyn Mawr, Llanelli, UK.

Received: 7 June 2018 Accepted: 25 October 2018 Published online: 23 November 2018

\section{References}

1. Nguyen ND, Ahlborg HG, Center JR, Eisman JA, Nguyen TV. Residual lifetime risk of fractures in women and men. J Bone Miner Res. 2007;22(6):781-8.

2. Rosengren BE, Karlsson MK. The annual number of hip fractures in Sweden will double from year 2002 to 2050: projections based on local and nationwide data. Acta Orthop. 2014:85(3):234-7.

3. Omsland TK, Emaus N, Tell GS, Magnus JH, Awad L, Holvik K, Forsmo S, Gjesdal CG, Schei B, Vestergaard P, et al. Mortality following the first hip fracture in Norwegian women and men ( 1999 - 2008 ). A NOREPOS study. Bone. 2014:63:81-6.

4. von Friesendorff M, McGuigan FE, Wizert A, Rogmark C, Holmberg AH, Woolf AD, Akesson K. Hip fracture, mortality risk, and cause of death over two decades. Osteoporos Int. 2016;27(10):2945-53.

5. Pedersen AB, Ehrenstein V, Szepligeti SK, Lunde A, Lagerros YT, Westerlund A, Tell GS, Sorensen HT. Thirty-five-year trends in first-time hospitalization for hip fracture, 1-year mortality, and the prognostic impact of comorbidity: a Danish nationwide cohort study, 1980-2014. Epidemiology. 2017;28(6): 898-905.

6. Mundi S, Pindiprolu B, Simunovic N, Bhandari M. Similar mortality rates in hip fracture patients over the past 31 years. Acta Orthop. 2014;85(1):54-9.

7. Jantzen C, Madsen CM, Lauritzen JB, Jorgensen HL. Temporal trends in hip fracture incidence, mortality, and morbidity in Denmark from 1999 to 2012. Acta Orthop. 2018:89(2):170-6.

8. Kärrholm JLH, Malchau H, Mohaddes M, Rogmark C, Rolfson O. Swedish hip arthroplasty register annual report 2015; 2016.

9. Cnudde P, Rolfson O, Timperley AJ, Garland A, Karrholm J, Garellick G, Nemes $S$. Do patients live longer after THA and is the relative survival diagnosis-specific? Clin Orthop Relat Res. 2018;476(6):1166-75.

10. Cnudde P, Rolfson O, Nemes S, Kärrholm J, Rehnberg C, Rogmark C, Timperley J, Garellick G. Linking Swedish health data registers to establish a research database and a shared decision-making tool in hip replacement. BMC Musculoskelet Disord. 2016:17(1):414

11. Elixhauser A, Steiner C, Harris DR. Comorbidity measures for use with administrative data. Med Care. 1998;36(1):8-27.

12. Quan H, Sundararajan V, Halfon P, Fong A, Burnand B, Luthi J-C, Saunders $L D$, Beck CA, Feasby TE, Ghali WA. Coding algorithms for defining comorbidities in ICD-9-CM and ICD-10 administrative data. Med Care. 2005; 43:1130.

13. Pohar M, Stare J. Relative survival analysis in R. Comput Methods Prog Biomed. 2006;81(3):272-8.

14. Pohar M, Stare J. Making relative survival analysis relatively easy. Comput Biol Med. 2007;37(12):1741-9.

15. Human life table database. http://www.lifetable.de/. 10 Apr 2018.

16. Human mortality data base. http://www.mortality.org/. 10 Apr 2018.
17. Stare J, Henderson R, Pohar M. An individual measure of relative survival. J R Stat Soc: Ser C: Appl Stat. 2005;54(1):115-26.

18. Stare J, Pohar M, Henderson R. Goodness of fit of relative survival models. Stat Med. 2005;24(24):3911-25.

19. Jurisson M, Raag M, Kallikorm R, Lember M, Uuskula A. The impact of hip fracture on mortality in Estonia: a retrospective population-based cohort study. BMC Musculoskelet Disord. 2017;18(1):243

20. Salkeld G, Cameron ID, Cumming RG, Easter S, Seymour J, Kurrle SE, Quine S. Quality of life related to fear of falling and hip fracture in older women: a time trade off study. BMJ. 2000;320(7231):341-6.

21. Magaziner J. Changes in functional status attributable to hip fracture: a comparison of hip fracture patients to community-dwelling aged. Am J Epidemiol. 2003;157(>11):1023-31.

22. Nightingale S, Holmes J, Mason J, House A. Psychiatric illness and mortality after hip fracture. Lancet. 2001;357(9264):1264-5.

23. Ariza-Vega P, Kristensen MT, Martín-Martín L, Jiménez-Moleón JJ. Predictors of long-term mortality in older people with hip fracture. Arch Phys Med Rehabil. 2015;96(7):1215-21.

24. Stenqvist C, Madsen CM, Riis T, Jorgensen HL, Duus BR, Lauritzen JB, van der Mark S. Orthogeriatric service reduces mortality in patients with hip fracture. Geriatr Orthop Surg Rehabil. 2016;7(2):67-73.

25. Lisk R, Yeong K. Reducing mortality from hip fractures: a systematic quality improvement programme. BMJ Qual Improv Rep. 2014;3(1):1-7.

26. Parker MJ. Reducing morbidity and mortality in the hip fracture patient group. Orthop Traumatol. 2016;30(2):153-8.

27. Gonzalez-Zabaleta J, Pita-Fernandez S, Seoane-Pillado T, Lopez-Calvino B, Gonzalez-Zabaleta JL. Comorbidity as a predictor of mortality and mobility after hip fracture. Geriatr Gerontol Int. 2016;16(5):561-9.

28. Smith T, Pelpola K, Ball M, Ong A, Myint PK. Pre-operative indicators for mortality following hip fracture surgery: a systematic review and metaanalysis. Age Ageing. 2014;43(4):464.

29. Hindmarsh D, Loh M, Finch CF, Hayen A, Close JC. Effect of comorbidity on relative survival following hospitalisation for fall-related hip fracture in older people. Australas J Ageing. 2014;33(3):E1-7.

30. Uriz-otano F, Pla-vidal J, Tiberio-lópez G, Malafarina V. Maturitas factors associated to institutionalization and mortality over three years, in elderly people with a hip fracture - an observational study. Maturitas. 2016:89:9-15.

31. Roche JJW, Wenn RT, Sahota O, Moran CG. Effect of comorbidities and postoperative complications on mortality after hip fracture in elderly people: prospective observational cohort study. BMJ. 2005;331(7529):1374.

32. Schnell S, Friedman SM, Mendelson DA, Bingham KW, Kates SL. The 1-year mortality of patients treated in a hip fracture program for elders. Geriatr Orthop Surg Rehabil. 2010;1(1):6-14.

33. Bülow E, Rogmark C, Cnudde P, Rolfson O, Garellick G, Nemes S. Comorbidity do not predict long-term mortality after total hip arthroplasty. Acta Orthop. 2017:14(Jun 14:1-6):1-6.

34. Kristensen PK, Thillemann TM, Johnsen SP. Is bigger always better? A nationwide study of hip fracture unit volume, 30-day mortality, quality of inhospital care, and length of hospital stay. Med Care. 2014;52:1023

35. Weller I, Wai EK, Jaglal S, Kreder HJ. The effect of hospital type and surgical delay on mortality after surgery for hip fracture. J Bone Joint Surg Br Vol. 2005:87(3):361-6.

36. Shah SN, Wainess RM, Karunakar MA. Hemiarthroplasty for femoral neck fracture in the elderly: surgeon and hospital volume-related outcomes. J Arthroplast. 2005;20:503

37. Klop C, Welsing PMJ, Cooper C, Harvey NC, Elders PJM, Bijlsma JWJ, Leufkens HGM, De Vries F. Mortality in British hip fracture patients, 20002010: a population-based retrospective cohort study. Bone. 2014:66:171-7.

38. Kim S-M, Moon Y-W, Lim S-J, Yoon B-K, Min Y-K, Lee D-Y, Park Y-S. Prediction of survival, second fracture, and functional recovery following the first hip fracture surgery in elderly patients. Bone. 2012;50(6):1343-50.

39. Thorne K, Johansen A, Akbari A, Williams JG, Roberts SE. The impact of social deprivation on mortality following hip fracture in England and Wales: a record linkage study. Osteoporos Int. 2016;27(9):2727-37.

40. Solbakken SM, Meyer HE, Stigum H, Søgaard AJ, Holvik K. Excess mortality following hip fracture: impact of self-perceived health, smoking, and body mass index. A NOREPOS study. Osteoporos Int. 2017:28(3):881-87.

41. Emami ARVMJ, Mahdaviazad BPH. Factors increasing mortality of the elderly following hip fracture surgery: role of body mass index, age, and smoking Musculoskelet Surg. 2017;101(1):25-29. 
42. Lofthus CM, Cappelen I, Osnes EK, Falch JA, Kristiansen IS, Medhus AW, Nordsletten L, Meyer HE. Local and national electronic databases in Norway demonstrate a varying degree of validity. J Clin Epidemiol. 2005;58(3):280-5.

43. Hockey R, Tooth L, Dobson A. Relative survival: a useful tool to assess generalisability in longitudinal studies of health in older persons. Emerg Themes Epidemiol. 2011;8(1):3.

44. Nordstrom P, Gustafson Y, Michaelsson K, Nordstrom A. Length of hospital stay after hip fracture and short term risk of death after discharge: a total cohort study in Sweden. BMJ. 2015;350:h696.

Ready to submit your research? Choose BMC and benefit from:

- fast, convenient online submission

- thorough peer review by experienced researchers in your field

- rapid publication on acceptance

- support for research data, including large and complex data types

- gold Open Access which fosters wider collaboration and increased citations

- maximum visibility for your research: over $100 \mathrm{M}$ website views per year

At $\mathrm{BMC}$, research is always in progress.

Learn more biomedcentral.com/submissions 